\title{
Higher Vocational College English Teaching and Learning Based on Embodied Cognition Theory
}

\author{
Nan Zhang \\ School of Foreign Languages \\ Chengdu Normal University \\ Chengdu, China
}

\begin{abstract}
Embodied cognition holds the view that human beings' cognition is fundamentally grounded in the body and external environment. In this paper, we summaries the problems in current higher vocational college English teaching and learning, analyzes the relation between embodied cognition theory and higher vocational English teaching and learning, and explores the embodied cognition strategy in teaching, attempting to help us understand what embodied cognition is in foreign language teaching and learning at a theoretical level and improve students' English application ability at a practical level.
\end{abstract}

Keywords-embodied cognition; English teaching; higher vocational college

\section{INTRODUCTION}

As a new generation of cognitive science thought, embodied cognition has exerted great influence and got academic responses on philosophy, cognitive psychology, linguistics, pedagogy and so on. According to this thought, cognition is not considered amodal and fundamentally different from perceiving and acting anymore. Instead cognition is seen as being dependent on the body. It considers the body as the main actor, and as such, as a key factor in shaping our cognition. In other words, cognition is at any time influenced by the morphology of our bodies and by its sensory-motor system. [1]

As far as the filed of pedagogy is concerned, researchers have done research mainly from the following three aspects home and abroad: first, exploring the teaching theory; second, exploring how to educate children; third, exploring the application of embodied cognition theory to classing teaching mainly in science subjects. Some researches have intended to explore the application of embodied cognition theory to English language teaching, mainly including its application to vocabulary acquisition, reading comprehension and children's English language acquisition.

The present article aims to discuss the inspiration and application of embodied cognition theory to higher vocational college English teaching with a focus on the role of students in the process of classroom performance. Its structure is as follows: first, it will briefly present the problems and characteristics of higher vocational college English teaching and learning in China, and then it will focus on the possibility and strategy of applying embodied cognition theory to the teaching and learning; it will end with conclusion and some open questions.

\section{CHARACTERISTICS AND PROBLEMS OF CURRENT HIGHER VOCATIONAL COLLEGE ENGLISH TEACHING AND LEARNING IN CHINA}

In recent years, with the rapid development of higher vocational education, the government's attaching importance to higher vocational education and the impact of higher vocational education on the development of the society, problems in higher vocational education development have aroused more and more concerns and researchers are paying more and more attention to every aspect of higher vocational education. Higher vocational college English teaching is one of the heated topics nowadays. However, there exist a lot of problems in current vocational college English teaching because of its own characteristics.

The problems concerning students mainly lie in the following aspects. First, higher vocational college students have different learning backgrounds. The main two components are the students who got much lower marks than those who entered undergraduate universities and college and the student who came from secondary vocational schools. For the former type, most of them choose to enter higher vocational colleges just because of their lower achievement in college entrance examination. Most of them do not have a good command of English, and even cannot meet the basic requirement for senior high school students. They cannot listen, speak, read and write smoothly, even they cannot pronounce correctly. For the second type, most secondary vocational schools especially in rural areas do not set English curriculum, therefore, those students have a much poorer command of English. Second, they have low impetus and interest. Just as what has been discussed above, because of their poor command of English, they have no self-confidence in English class and do not want to participate in class activities. In class, most of them keep silence or do not concentrate. According to relevant questionnaire and investigation, most students have insufficient learning motivation. Some students have positive attitude toward English learning. They know clearly that English is important in the future and have certain degree of interest in it, but their English foundation is so poor and they have no idea and insistence in leaning. Some students have negative attitude toward English learning. They do not think English is 
important and useful in their future jobs and the colleges have no special requirement for students' English level, therefore, the students have neither internal nor external English learning pressure.

As for teachers, because of the shortage of teaching staff, most English teachers have overburdened work quantities, therefore they do not have enough energy in curriculum reform. Moreover, because of students' present learning situation, teachers may just follow the teaching material, lack of fully and actively pondering on teaching arrangement and students' cognitive features. The teaching attaches little importance on students' body experience and body activities, in this way, English class mainly focus on students' neck-above study, which may not fully meet the needs of the students and make them lose interest in English learning.

\section{THEORETICAL BACKGROUND}

\section{A. Connotations of Embodied Cognition}

In 1980s, a number of alternative perspectives emerged within cognitive science, originating in different disciplines, but sharing a commitment to investigating cognition as physically-embodied phenomenon, realized via a process of codetermination between the organism and the medium in which it exists.[2] Embodied cognition holds that many features of cognition are embodied in that they are deeply dependent upon characteristics of the physical body of an agent such that the agent's beyond-the-brain body plays a significant causal role, or a physically constitutive role, in that agent's cognitive processing.[3]

Embodied cognition theory holds that human beings' cognition is inextricably related to the human body and the external environment, emphasizing the importance of human body in the cognitive process. Language itself presents an embodied model that body is the carrier of language formation and development, and language is a kind of body interactional activity. At a foundational level, our analysis builds on work by Wilson and Lakoff and Johnson in cognitive linguistics. All these scholars share a focus on the close relation between cognition and body experience in the world.

\section{B. Relation between Embodied Cognition and Teaching and Learning}

According to existing researches, it is proved that embodied cognition theory can lay theoretical foundation and provide practical guidance for foreign language teaching. The main guiding principles applied in this article are as follows. First, cognition is based on human body. Human body should be involved in cognition and language is acquired within the body. In English teaching and learning, human body should be physiologically involved. Students can acquire related knowledge by such activities as watching, listening, speaking, singing, dancing, and playing. Second, cognition is situated. Cognition takes place in the real world, and it is real-time, situated, dynamic and developmental. When designing teaching activities, the teacher should pay attention to the construction of learning situation, taking such factors as learners' learning style, learning needs and learning time into consideration. Nowadays, multimedia and network are playing a more and more important role in helping to construct the situation.

\section{APPLICATION OF EMBODIED COGNITION THEORY TO HighER VOCATIONAL COLLEGE ENGLISH}

From the above discussion on features of the present situation of higher vocational college English teaching and learning in China and the relationship between embodied cognition theory and foreign language acquisition, it is possible and feasible to apply embodied cognition theory to higher vocational college English teaching and learning.

\section{A. Application in Vocabulary Acquisition}

Vocabulary is the foundation for learning a foreign language. However, according to relevant research, we know that many higher vocational college students have difficulty in acquiring enough English vocabulary to meet the requirement for daily communication. They have formed the habit of memorizing English words letter by letter. When they meet those words with complex spelling, they feel quite pained and gradually lose interest and confidence in memorizing English words in this way. Actually, embodied cognition theory can be applied to the teaching and learning of English words' pronunciation, spelling and meaning. When teaching pronunciation, teachers can use gestures to correct students' pronunciation. For example, in order to help Chinese students to distinguish the difference of long vowel and short vowels, teachers can ask students to put their fingers into their mouths to feel the different status of the mouth and the tongue. Moreover, the rate of clapping hands and stamping feet can help to master the word stress, which is also a headache for Chinese students. As to the comprehension and application of English words, besides the involvement of human body, the situation can be constructed with the aid of multimedia and network. Expressions, gestures, behavior and constructing a certain situation for students to do role-play can be applied to the learning of verbs, nouns and prepositions.

\section{B. Application in Listening And Speaking}

The current major aim of higher vocational college English teaching is to cultivate students' English application ability in their future jobs. Therefore, it is important to construct real situation in listening and speaking activities. In class, situational activities related with the input and output of the required words, phrases and sentences should be designed to make students feel and experience to master the required language points and achieve teaching goals. Moreover, multimedia language situation with the aid of online listening, video teaching, MOOC, and App can be constructed to help students participate in learning and practice.

\section{Application in Reading and Writing}

From the perspective of embodied cognition theory, reading and writing are considered as the experience process of a person's physical and mental coordination and integration with situation. In the process, we should make a concrete analysis of the abstract symbolized content to achieve our own 
understanding and attach importance to the cultural significance of English learning, including knowing about foreign cultures, experiencing culture shocks, and forming personal values, which all need the participation of human beings' own body experience and mind. For example, in the process of reading comprehension, the sympathy with the text and the author is everlasting. Students should enter the world of the text first and then relate the situation with the text and achieve their own understanding and production finally.

\section{ENLIGHTENMENT AND CHALLENGES}

First, the application of embodied teaching strategy can help to stimulate students' English learning interest. This application emphasizes students' body participation. In the teaching process, teachers always focus on students' physical and mental development, guiding students to actively perceive and experience by their head, ears, mouth, hands and so on. Meanwhile, all kinds of games and plays are provided with the aid of multimedia and network.

Second, the application of embodied teaching strategy can help to enhance students' English application ability. From the above analysis, we know that students' pronunciation, vocabulary learning, speaking can be effectively improved especially for those with a poor command of English. However how to effectively improve listening, reading and writing still needs more consideration because of the complicatedness of human beings' cognition features. Furthermore, the integration with multimedia and network technology is also a big problem for English teachers.

Third, the application of embodied teaching strategy can help to achieve a harmonious teacher-student and studentstudent relation. In this kind of class, students are no longer fixed to their seats but can communicate with the teacher and classmates much more relaxed. In order to fulfill the required activities, there are chances for communication between teachers and students.

However, there are still challenges in many aspects. First, the construction of situation needs advanced multimedia equipments. However, many vocational colleges have not attached enough importance to it. Second, teachers' thoughts and practice cannot catch up with the theory. In this kind of class, teachers should hold the view that students are the center while teachers mainly play the role of the guide and organizer. In the teaching process, teachers should guide students to learn to question and create, and enhance autonomous learning. When there appears difference in the embodied process from the known experience or knowledge, students should be cultivated to explore the reasons and find out solutions. Meanwhile, teachers should encourage and guide students to study after class based on their own embodied cognitive features. That is to say, teachers must spend more time and energy in exploring theory and practice. Third, there are more and strict requirements for students. Students should take part in these activities both physically and mentally, which may make them feel anxious and unconfident.

\section{CONCLUSION}

The present article summaries the problems in current higher vocational college English teaching and learning, analyzes the relation between embodied cognition theory and higher vocational English teaching and learning, and explores the embodied cognition strategy in teaching, attempting to help understand what embodied cognition is in foreign language teaching and learning at a theoretical level and improve students' English application ability at a practical level.

However, there are some problems and limitations. First, the theory of embodied cognition itself faces some challenges. For example, will it properly explain abstract cognitive content too?[4] will this approach become mainstream cognitive science as some already argue?[5] we have not got definite answers for these questions. In the future, more researches at theoretical levels should be done. Second, more empirical tests should be done to verify the claims of embodied cognition. Can embodied cognition strategy be applied to a larger scope? Can embodied cognition strategy effectively improve students' English application ability in all aspects including listening, speaking, reading, writing and translation and how could it be? All these need further studies.

First, higher vocational college English teaching and learning has embodied feature, and it is feasible to apply the related embodied cognition theory to practice.

\section{REFERENCES}

[1] A. M. Glenberg, "Embodiment as a unifying perspective for psychology," Advanced Reviews. John Wiley \& sons Ltd., I, 586-596.

[2] M. Wilson, "Six views of embodied cognition," Psychonomic bulletin \& review, 2002, 9(4): 625

[3] G. Lakoff, and M. Johnson. Philosophy In The Flesh: the Embodied Mind and its Challenge to Western Thought. Basic Books, 1999: 3-36.

[4] M. Wilson. "How Did We Get from There to Here? An Evolutionary Perspective on Embodied Cognition," in P. Calvo \& A. Gomila, Eds. Handbool of Cognitive Science: An embodied Approach, San Diego: Elsevier, 2008.

[5] A. Laakso, "Embodiment and development in cognitive science," Cognition, Brain, Behavior: An Interdisciplinary Journal(Special Issue: Embodiment and Development), 2011, 15, pp409-425.

[6] J. G. Greeno, and J.L. Moore, "Situativity and symbols: Response to Vera and Simon,” Cognitive Science. 1993,17, pp49-59. 